\title{
Aggregation of Platelets by Collagen
}

\author{
G. D. Wilner, H. L. Nossel, and E. C. LeRoy \\ From the Departments of Medicine and Pathology, College of Physicians and \\ Surgeons, Columbia University, New York 10032
}

A B S T R A C T In studying some of the properties of collagen responsible for the ability to aggregate platelets it was found that thermal treatment at $\mathrm{pH} 2.5$ of acid-soluble human collagen resulted in a sharp reduction in relative viscosity and platelet aggregating activity at about $35^{\circ} \mathrm{C}$. The reduction in viscosity is known to be associated with structural transition from triple helical to random coil form and it is postulated that the native structure of collagen is essential for its platelet aggregation effect. Blockage of the free amino groups by deamination, $N$-acetylation, or treatment with dinitrofluorobenzene resulted in over $90 \%$ reduction in platelet aggregating activity. Addition of cationic proteins to collagen, removal of the negatively charged telopeptides by treatment with pepsin, or acetylation of the free carboxyl groups did not significantly affect the platelet aggregating activity of collagen. On the basis of these findings it is suggested that the free amino groups and specifically the epsilon amino groups of lysine are critical for the platelet aggregating activity of collagen whereas the carboxyl groups are of relatively little importance.

\section{INTRODUCTION}

Purified collagen (1) and other preparations of collagen (2-6) have been shown to aggregate platelets. and it has been postulated on the basis of light and electron microscopic studies that vessel wall collagen plays an important role in normal hemostasis by initiating platelet plug formation (6-11). It is thought that platelets first adhere to collagen without requirement for divalent cations or plasma cofactors (12). Platelet adenosine diphosphate is then released and associated with ag-

Reccized for publication 25 June 1968. gregation of further platelets; calcium ions and at least one plasma cofactor are required (2). The properties of collagen which cause the reaction with platelets are not known and it is the purpose of the present communication to describe the results of some studies of this problem. These studies were carried out simultaneously with an investigation of the action of collagen on plasma coagulation (13).

\section{METHODS}

Platelet-rich plasma was prepared by centrifuging at room temperature $\left(27^{\circ}\right)$ for $20 \mathrm{~min}$ at $500 \mathrm{~g}$ blood collected as previously described (13). With the use of a silicone-treated pipette the supernatant plasma was transferred to a polystyrene tube (Falcon, Will Scientific of N.Y.C., Inc., New York 10023) which was stoppered and kept at room temperature throughout the test procedure. The platelets were counted by direct light microscopy after dilution with Rees-Ecker diluting fluid (14). The plasma was diluted with platelet-poor plasma from the same donor so that the platelet count was $250,000 \pm 25,000$ / $\mathrm{mm}^{8}$ except where specified otherwise. Platelet-poor plasma was prepared by centrifuging fresh citrated whole blood three times at $20,000 \mathrm{~g}$ at $4^{\circ} \mathrm{C}$. The platelet count was less than $400 / \mathrm{mm}^{3}$. The tests were carried out between 75 and 180 min after drawing the blood.

Calcium chloride and barbital-buffered saline $(\mathrm{pH}$ 7.40) were prepared as previously described (13). Russell's viper venom was obtained from Burroughs Wellcome \& Co., Inc., Tuckahoe, N. Y.

Collagen prepared from human skin by the Nishihara method was used throughout (13) except for the thermal denaturation studies, which employed acid soluble fetal skin collagen (13). Collagen preparations were suspended in saline at $4^{\circ} \mathrm{C}$ as previously described (13). Thermal denaturation, pepsin treatment, $\epsilon$-amino blockage with dinitrofluorobenzene, deamination, acetylation of the carboxyl groups, and digestion of the collagen with collagenase were carried out as previously described (13) $N$ and $O$-acetylated collagen was prepared as follows (15): $100 \mathrm{mg}$ collagen was stirred constantly at room temperature $\left(27^{\circ} \mathrm{C}\right)$ for $72 \mathrm{hr}$ with $100 \mathrm{ml}$ glacial acetic acid and $100 \mathrm{ml}$ acetic anhydride. The product was deposited by 
centrifugation at $5000 \mathrm{~g}$ for $20 \mathrm{~min}$, washed six times with cold acetone, air-dried on a sintered glass suction filter, and stored at $-60^{\circ} \mathrm{C}$. $N$-acetylated collagen was prepared by $18 \mathrm{hr}$ dialysis of a $1 \mathrm{mg} / \mathrm{ml} N$ - and $O$-acetylated collagen suspension in saline against $0.05 \mathrm{~N} \mathrm{NaOH}$. The collagen suspension was then dialyzed against Veronalbuffered saline ( $\mathrm{pH} \mathrm{7.4)}$ for $6 \mathrm{hr}$ and tested.

Platelet coagulant activity (platelet factor 3 ). was tested as follows (16). The clotting mixtures consisted of $0.1 \mathrm{ml}$ platelet-rich plasma, $0.1 \mathrm{ml}$ saline, and $0.1 \mathrm{ml}$ addition incubated for $20 \mathrm{~min}$ at $37^{\circ} .0 .1 \mathrm{ml}$ Russell's viper venom $(10 \mu \mathrm{g})$ and $0.1 \mathrm{ml} \mathrm{CaCl} 20.025 \mathrm{M}$ were then added and the clotting time recorded. Platelet aggregation was measured by a turbidimetric method as described by Born (17). A temperature controlled $\left(37^{\circ}\right)$ cuvette holder with magnetic stirrer $(1400 \mathrm{rpm})$ was used in a Zeiss PMQ II spectrophotometer ${ }^{1}$ with the monochromator set at $600 \mathrm{~m} \mu$ and the slit width at $0.3 \mathrm{~mm} .1 .2 \mathrm{ml}$ plateletrich plasma and $0.2 \mathrm{ml}$ saline were added to a $1.5 \mathrm{~cm}$ wide silicone-treated glass cuvette and after equilibration with stirring for $1 \mathrm{~min} 0.1 \mathrm{ml}$ of the test addition (collagen suspension or saline) was added. Aggregation was recorded on a Honeywell Elektronik 19 recorder $^{2}$ as change in light transmission. The blank consisted of 0.3 $\mathrm{ml}$ saline and $1.2 \mathrm{ml}$ platelet-poor plasma from the same blood sample as the platelet-rich plasma.

The platelet aggregation curves were analysed by dividing the curve into delay and aggregation phases. The delay phase extends from the point of collagen addition to the point where the curve is elevated from the base line by one transmission unit. The slope of the aggregation phase is defined as the rate of change in light transmission when a steady state is reached, and the amplitude as the number of light transmission units between the base line and the asymptotic part of the aggregation curve. When the reproducibility of the test was examined by recording the curves resulting from addition of $100 \mu \mathrm{g}$ collagen 12 times to platelet-rich plasma samples from the same specimen of blood the delay phase was $75 \mathrm{sec}$ with a standard deviation of $10 \mathrm{sec}$. The slope was 14.8 transmission units/min with a standard deviation of 2 units/minute and the amplitude was 41.5 transmission units with a standard deviation of 0.8 units. Since amplitude was the most reproducible measure it was used as the chief criterion for quantifying platelet aggregation.

The effect of varying the platelet count while maintaining the collagen concentration constant is shown in Fig. 1. Optimal amplitude occurred with counts between 200,000 and $300,000 / \mathrm{mm}^{3}$. When the platelet count was constant and the collagen concentration varied a set of curves was obtained as in Fig. 2. With collagen concentrations below a critical level (about $15 \mu \mathrm{g}$ ) the curve of platelet aggregation was sensitive to small changes in concentration, the slope and amplitude of the aggregation curve showing the greatest changes.

The activity of collagen modified in various ways was compared with the activity of control collagen preparations by testing each collagen preparation at serial con-

${ }^{1}$ Carl Zeiss, Inc., New York.

2 Honeywell, Inc., Long Island City, N. Y.

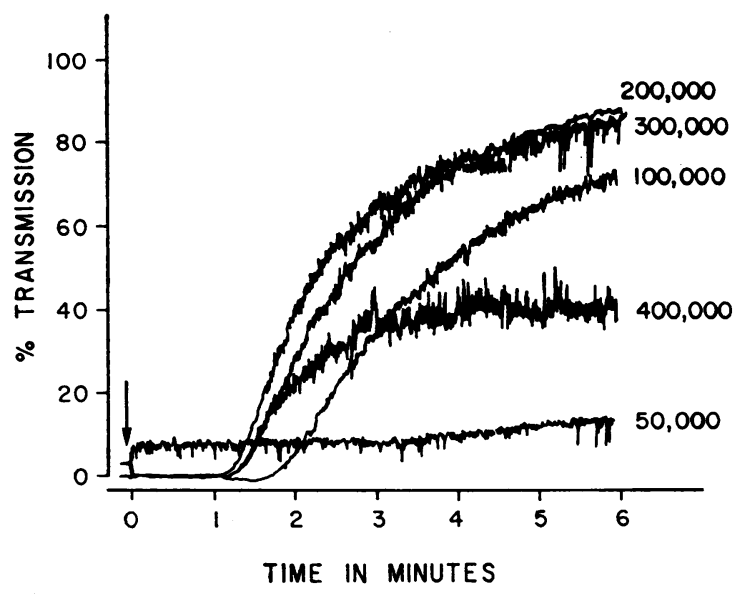

FIGURE 1 Platelet aggregation curves with varying platelet counts and a constant amount of collagen (100 $\mu \mathrm{g})$. The different curves have been drawn so that their origins are near the baseline.

centrations and comparing the platelet aggregation curves with those resulting when similar control collagen concentrations were tested.

\section{RESULTS}

Collagenase digestion of collagen resulted in complete loss of activity against platelets, confirming that collagen was the active substance. Heating collagen solutions to various temperatures for 30 min resulted in a sharp reduction in viscosity and a parallel loss of platelet aggregating ability at about $35^{\circ}$ (Fig. 3). Pepsin treatment of collagen, which removes the telopeptides, resulted in pro-

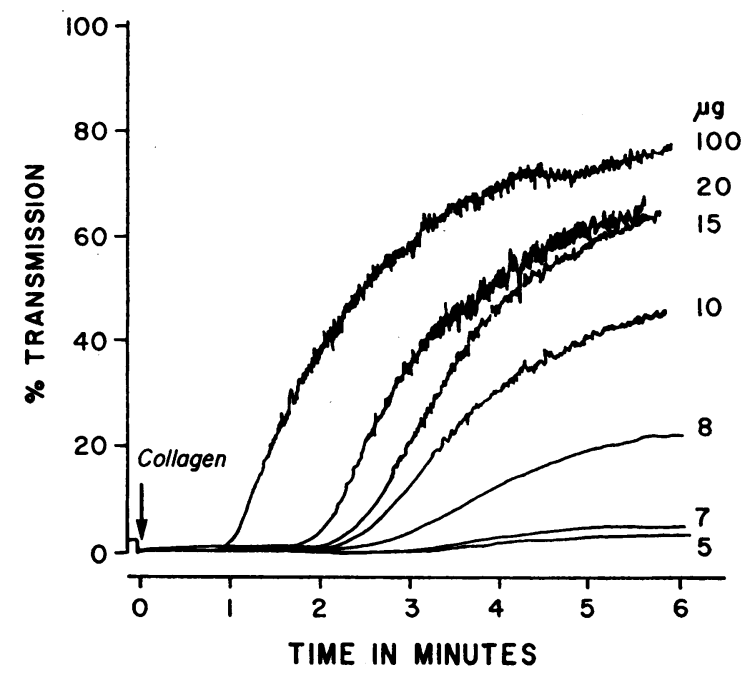

Figure 2 Platelet aggregation curves with varying collagen concentration and constant platelet count $(250,00 /$ $\mathrm{mm}^{3}$ ). 


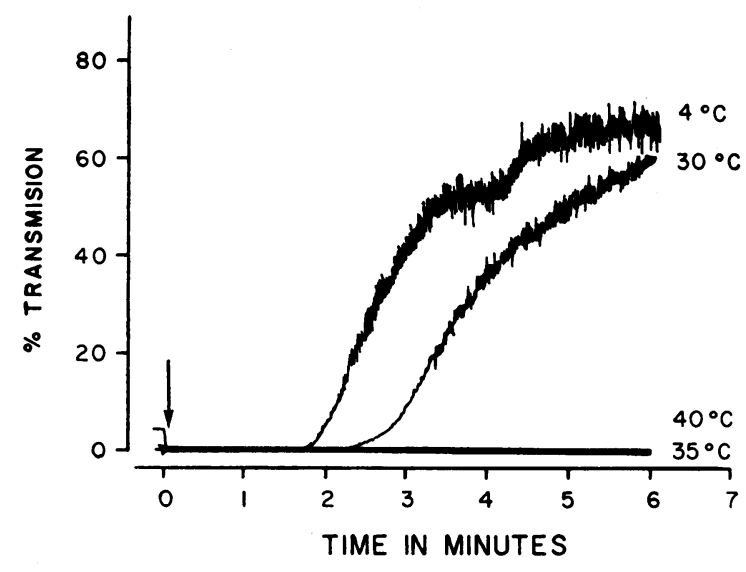

Figure 3 The effect of thermal treatment on the platelet aggregating activity of collagen. ( $40 \mu \mathrm{g}$ collagen was tested in each experiment.)

longation of the delay phase of platelet aggregation but neither the slope nor the amplitude of aggregation was altered even with amounts as low as $5 \mu \mathrm{g}$ (Fig. 4). Blockage of the epsilon amino groups of lysine by treatment with dinitrofluorobenzene (23) resulted in more than 95\% reduction in platelet aggregating activity (Fig. 5, Table I). Similar loss of activity resulted from $N$-acetylation, $N$ - and $O$-acetylation, or diazotization of the collagen with nitrous acid. In contrast, acetylation of the carboxyl groups by treatment with methanol (23) resulted either in no change or in a slight increase in platelet aggregating activity (Fig. 6 ) but the ability to increase the coagulant activity of platelets was slightly reduced (Table I). Addition of positively charged substances such as cytochrome $c$, spermine, or lysozyme did not significantly alter platelet aggregating activity.
TABLE I

Effect of Collagen on Platelet Coagulant Activity in the Presence of Russell's Viper Venom

\begin{tabular}{lc}
\hline \multicolumn{1}{c}{ Addition } & Clotting time \\
\hline & sec \\
Saline & 32.8 \\
Control collagen & 22.7 \\
DNFB-treated collagen & 30.4 \\
Methanol-treated collagen & 26.4 \\
Pepsin-treated collagen & 27.3
\end{tabular}

The clotting mixtures consisted of $0.1 \mathrm{ml}$ platelet-rich plasma, $0.1 \mathrm{ml}$ saline, and $0.1 \mathrm{ml}$ addition incubated for 20 $\min$ at $37^{\circ} .0 .1 \mathrm{ml}$ Russell's viper venom $(10 \mu \mathrm{g})$ and $0.1 \mathrm{ml}$ $\mathrm{CaCl}_{2} \mathrm{O}_{2025} \mathrm{M}$ were then added and the clotting time recorded. $25 \mu \mathrm{g}$ of collagen was added in each instance.

\section{DISCUSSION}

The method used to quantify platelet aggregating activity by comparing aggregation curves obtained with different amounts of collagen gave reproducible results. Evidence that the collagen molecule itself reacts with the platelets is provided by the results of the experiment in which collagenasedigested preparations did not cause platelet aggregation (Fig. 3). This result confirms the previous findings of Zucker and Borrelli (1). Addition of collagenase to collagen immediately before the test did not affect the activity of collagen, thus excluding the possibility that the collagenase may have affected either plasma or platelets. The loss of activity of collagen heated to above $35^{\circ} \mathrm{C}$ in solution provides additional evidence that the collagen molecule itself produces platelet aggregation.

The parallel reduction in viscosity and loss of activity on heating suggests that the native collagen.

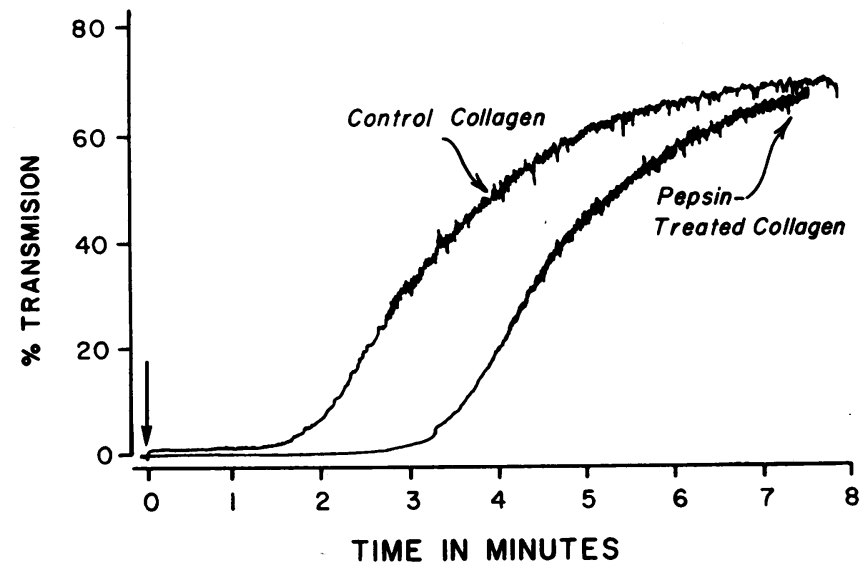

2618 G. D. Wilner, H. L. Nossel, and E. C. LeRoy
FigURE 4 The effect of pepsin-treated collagen on platelet aggregation. ( $5 \mu \mathrm{g}$ collagen was tested in each experiment.) 

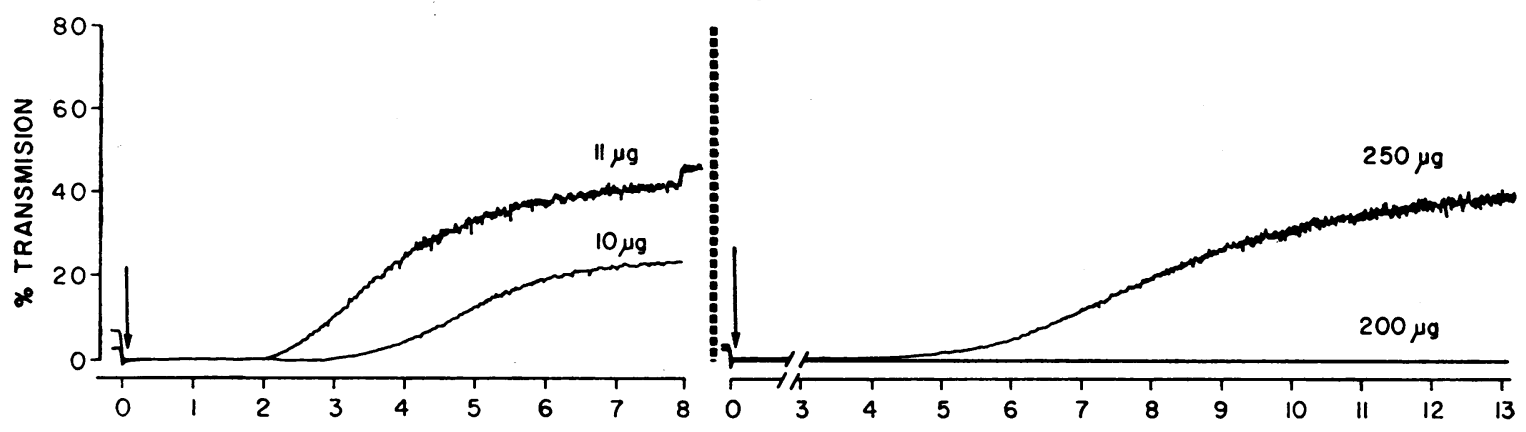

TIME IN MINUTES

Figure 5 The effect of dinitrofluorobenzene treatment of collagen on its ability to aggregate platelets. $A$ represents control collagen and $B$ represents dinitrofluorobenzene-treated collagen.

helix is necessary for activity since the decrease in viscosity parallels a transformation from helical to random coil structure $(19,20,27)$. It is possible that random coils are inactive because of mutual neutralization of binding sites, because a rigid structure is necessary to activate platelets, or because collagen in solution is inactive. On the other hand, Zucker (6) has reported that collagen in solution aggregates platelets.

Blocking the basic groups on collagen has a profound effect on its platelet aggregating activity. Nitrous acid treatment of collagen, which results in almost $100 \%$ replacement of the free amino groups by hydroxyl groups and about $20 \%$ conversion of the free guanidyl groups into cyanamide groups (15) results in loss of more than $90 \%$ platelet aggregating activity. $N$-acetylation of collagen which results in complete acetylation of the free amine groups of lysine and hydroxylysine (21) also resulted in loss of over $90 \%$ platelet aggregating activity. Treatment of collagen with dinitrofluorobenzene blocks about $70 \%$ of the epsilon amino groups of lysine (22) and is also associated with over $90 \%$ reduction in activity. It therefore seems likely that the free amino groups in general and the epsilon amino groups of lysine specifically are critical for the platelet aggregating activity of collagen.

In contrast, blocking the acidic groups of collagen appeared to have little effect. Methanol treatment of collagen esterifies $80-90 \%$ of the glutamic and aspartic carboxyl groups (23). Collagen treated in this way appeared to aggregate platelets just as actively or more actively than the control collagen (Fig. 6). The lack of effect of positively charged substances supports the view

\section{A}

B

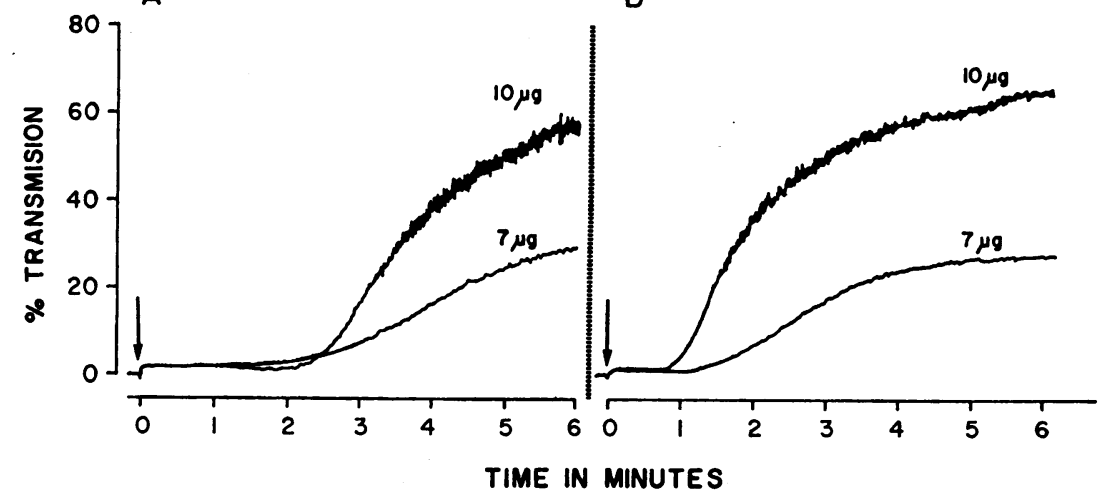

FIGURE 6 The effect of methanol treatment of collagen on its ability to aggregate platelets. $A$ represents control collagen and $B$ represents methanol-treated collagen. 
that the negatively charged sites on the collagen molecule are not critical for collagen-induced platelet aggregation.

The effect of modified collagen in increasing platelet coagulant activity indicates that the reduced ability of the DNFB collagen to increase platelet coagulant activity correlates with the reduced platelet aggregating activity of this preparation. This result was to be expected since Hardisty and Hutton (24) have shown that platelet coagulant activity is correlated with platelet aggregation. It is not clear why the methanol- and pepsin-treated collagen preparations increased platelet coagulant activity less effectively but all the factors involved in the production of platelet coagulant activity are not known.

Previous work has indicated that telopeptide removal from collagen does not affect adhesion (25) or aggregating activity (26) and the present findings are in agreement (Fig. 5). The delay phase was, however, lengthened with pepsin-treated collagen. This finding was reproducible but its meaning is not clear.

The most interesting aspect of the results of this investigation is the complete dissociation found between the ability of different collagen preparations to activate platelets and Hageman factor (13). The negatively charged carboxyl groups of glutamic and aspartic acids appear to be critical for the ability to activate Hageman factor but not important for the ability to aggregate platelets, whereas the positively charged epsilon amino groups of lysine appear to be critical for the ability to aggregate platelets but not for the ability to activate Hageman factor.

\section{ACKNOWLEDGMENTS}

We wish to thank Dr. Karl Meyer for his kindly interest and helpful discussions and Mrs. Rosario Hsieh and Mr. Michael Drillings for their excellent technical work.

This work was supported in part by NIH grants HE 10999, HE 05741, and T01 CA 05151, and grants from the U. S. Public Health Service, The RGK Foundation, Austin, Texas, and the John A. Hartford Foundation, New York.

\section{REFERENCES}

1. Zucker, M. B., and J. Borrelli. 1962. Platelet clumping produced by connective tissue suspensions and by collagen. Proc. Soc. Exptl. Biol. Med. 109: 779.
2. Bounameaux, Y. 1961. L'accolement des plaquettes aux fibres sousendothéliales. Thromb. Diath. Haemorrhag. 6: 504 .

3. Hugues, J. 1962. Accolement des plaquettes aux structures conjonctives périvasculaires. Thromb. Diath. Haemorrhag. 8: 241.

4. Hovig, T. 1963. Aggregation of rabbit blood platelets produced in vitro by saline "extracts" of tendons. Thromb. Diath. Haemorrhag. 9: 248.

5. Hugues, J., and C. M. Lapière. 1964. Nouvelles recherches sur l'accolement des plaquettes aux fibres de collagène. Thromb. Diath. Haemorrhag. 11: 327.

6. Zucker, M. B. 1967. ADP and collagen induced platelet aggregation in vivo and in vitro. Thromb. Diath. Haemorrhag. Supp. 26: 175.

7. Hugues, J. 1959. Agglutination précoce des plaquettes au cours de la formation du clou hemostatique. Thromb. Diath. Haemorrhag. 3: 177.

8. Spaet, T. H., and R. B. Erichson. 1966. The vascular wall in the pathogenesis of thrombosis. Thromb. Diath. Haemorrhag. Supp. 21: 67.

9. Ashford, T. P., and D. G. Freiman. 1967. The role of endothelium in the initial phase of thrombosis. Am. J. Pathol. 50: 257.

10. Ts'ao, Chung-Hsin, and T. H. Spaet. 1967. Ultramicroscopic changes in the rabbit inferior vena cava following partial constriction. Am. J. Pathol. 51: 789.

11. Hovig, T., L. Jorgensen, M. A. Packham, and J. F. Mustard. 1968. Platelet adherence to fibrin and collagen. J. Lab. Clin. Med. 71: 29.

12. Spaet, T. H., and M. B. Zucker. 1964. Mechanism of platelet plug formation and role of adenosine diphosphate. Am. J. Physiol. 206: 1267.

13. Wilner, G. D., H. L. Nossel, and E. C. LeRoy. 1968. Activation of Hageman factor by collagen. J. Clin. Invest. $47: 2608$.

14. Wintrobe, M. M. 1967. Clinical Hematology. Lea \& Febiger, Philadelphia, $\mathrm{Pa}$. 6th edition. 303.

15. Bowes, J. H., and R. H. Kenten. 1949. The effect of deamination and esterification on the reactivity of collagen. Biochem. J. 44: 142.

16. Spaet, T. H., and J. Cintron. 1965. Studies on platelet factor-3 availability. Brit. J. Haematol. 11: 269.

17. Born, G. V. R. 1962. Aggregation of blood platelets by adenosine diphosphate and its reversal. Nature. 194: 927.

18. Olcott, H. S. and H. Fraenkel-Conrat. 1947. Specific group reagents for proteins. Chem. Rev. 41: 151.

19. Burge, R. E., and R. D. Hynes. 1959. The thermal denaturation of collagen in solution and its structural implications. J. Mol. Biol. 1: 155.

20. Engel, J. 1962. Investigation of the denaturation and renaturation of soluble collagen by light scattering. Arch. Biochem. Biophys. 97: 150.

21. Green, R. W., K. P. Ang, and L. C. Lam. 1953. Acetylation of collagen. Biochem. J. 54: 181.

22. Veis, A. 1967. Intact collagen. In Treatise on Collagen. G. N. Ramachandran, editor. Academic Press, Inc., New York. 1: 378. 
23. Gustavson, K. H. 1956. The Chemistry and Reactivity of Collagen. Academic Press Inc., New York.

24. Hardisty, R. M., and R. A. Hutton. 1966. Platelet aggregation and availability of platelet factor 3. Brit. J. Haematol. 12: 764.

25. Wojtecka-Lukasik, E., I. Sopata, J. Wize, M. Skonieczna, I. Niedzwiecka-Namyslowska, and' E. Ko- walski. 1967. Adhesion of platelets to collagen devoid of telopeptides. Thromb. Diath. Haemorrhag. 18: 76.

26. Róka, L. 1967. Discussion on the role of ADP in platelet aggregation. Thromb. Diath. Haemorrhag. Supp. 26: 201.

27. Schmitt, F. O., L. Levine, M. P. Drake, A. L. Rubin, D. Pfahl, and P. L. Davison. 1964. The antigenicity of tropocollagen. Proc. Nat. Acad. Sci. U. S. 51: 493. 